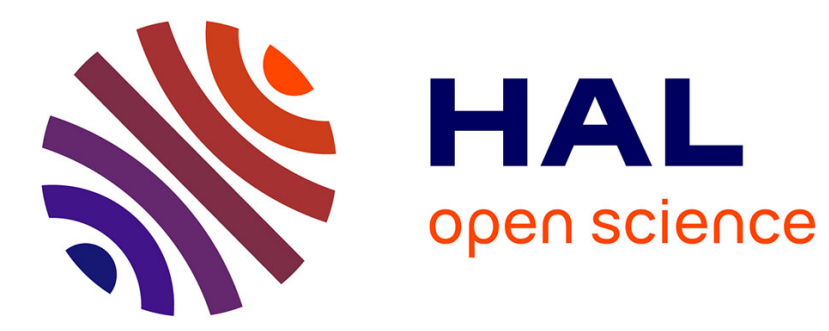

\title{
'He's a cop but he isn't a bastard': an enunciative approach to some pragmatic effects of the coordinator but. \\ Martine Sekali
}

\section{To cite this version:}

Martine Sekali. 'He's a cop but he isn't a bastard': an enunciative approach to some pragmatic effects of the coordinator but.. John Benjamins Publishing Company. Connectives as Discourse Landmarks, John Benjamins Publishing Company, pp.230-260, 2007, Pragmatics \& Beyond New Series, 161. halshs-00529047

\section{HAL Id: halshs-00529047 https://shs.hal.science/halshs-00529047}

Submitted on 24 Oct 2010

HAL is a multi-disciplinary open access archive for the deposit and dissemination of scientific research documents, whether they are published or not. The documents may come from teaching and research institutions in France or abroad, or from public or private research centers.
L'archive ouverte pluridisciplinaire HAL, est destinée au dépôt et à la diffusion de documents scientifiques de niveau recherche, publiés ou non, émanant des établissements d'enseignement et de recherche français ou étrangers, des laboratoires publics ou privés. 


\title{
'He's a cop but he isn't a bastard': an enunciative approach to some pragmatic effects of the coordinator but.
}

\author{
Martine SEKALI \\ CREA-GREG \\ Université de Paris Ouest Nanterre La Défense
}

published in Connectives as Discourse Landmarks, John Benjamins Publishing Company, Pragmatics \& Beyond New Series, 161, 2007

\begin{abstract}
This paper uses the Theory of Enunciative Operations and suggests new concepts for a linguistic analysis of 'pragmatic' effects such as the construction, through the use of grammatical markers, and connectives in particular, of indirect meaning, and argumentative force. Defining a three-term relation, the coordinator but is considered here as a counter-subordinator which both creates an argumentative domain attributed by the speaker to a previous utterance and corrects it in an interpersonal relation of discordance with the addressee. We propose a detailed contextualized analysis of the construction and retrieval of implicit utterances and argumentative power in interviews and political debates as the result of enunciative (versus extra-linguistic) operations marked by but interacting with a combination of specific markers within the utterances it links.
\end{abstract}




\section{Preliminary remarks}

My purpose here is to analyse the linguistic and enunciative process by which the coordinator $\boldsymbol{b u t}$, interacting with the inner structures of the utterances it links, can build argumentative effects that have so far been analysed mainly with the tools of pragmatics and logic. Using the concepts developed within the Theory of Enunciative Operations (T.E.O), ${ }^{1}$ I will consider the construction of indirect meaning, or implicit utterances, as well as the positioning of the speaker with respect to mental representations which are attributed to the addressee. I will also consider the notion of 'argumentative force' of utterances as the result of linguistic (versus extra-linguistic) operations marked by a combination of specific markers.

This paper will also raise a few questions as to the method for approaching such pragmatic values in linguistics. Indeed, argumentation being a linguistic phenomenon, (unless of course one comes to blows..), how can we provide a useful description of the linguistic operations involved in argumentative phenomena, and particularly, of the subjective relations (or inter-personal positions) which are constructed through the use of specific markers? Argumentative (or qualitative) connection has been widely studied by linguists interested in the logical ordering and semantic presuppositions of connected notions. It has also been studied within the framework of pragmatics where the extra-linguistic context is a major parameter for the analysis of speech acts and indirect meaning. ${ }^{2}$ So it is worth noting that what, originally, is a properly linguistic phenomenon, appears to be very difficult to apprehend with intra-linguistic tools.

One of the reasons for this difficulty is the fact that, through argumentative subordination or coordination, an utterance is given a power it does not necessarily 
have on its own. When using argumentative connectives, the speaker asserts that one of the utterances has the power to validate or invalidate the other one, or more precisely, that the subjective endorsement of an utterance enables or, on the contrary, prevents the endorsement of the other one.

Another question is the level of the utterance on which the connective operates. When dealing with argumentative connection, we must consider that the connective does not only link predicates, or arguments, but whole utterances, the dictum and the modus, therefore complex notional domains. ${ }^{3}$ In that respect, it is reasonable to say that argumentative connectives do not only mark a logico-semantic link between notions, they construct a double set of relations.

First of all, a subjective (and inter-subjective) relation is defined on the endorsement of utterances (therefore an operation of subjective anchoring, or subjective location): who accepts the utterance as true and do speaker and addressee agree or disagree on this truth? It is important to note here that I will use the terms speaker and addressee with the theoretical status of the French 'énonciateur' and 'co-énonciateur', i.e. as origins of endorsement and modality in utterances. In the sense of 'énonciateur', the speaker is to be understood as an abstract linguistic entity, a subjective origin, and not a 'locuteur' actually producing speech, except of course in a situation of dialogue. Likewise, the addressee is to be considered as a linguistic construct, a product of discourse rather than a discourse producer, although it can become an interlocutor (or co-speaker) in a dialogical context. The addressee is therefore to be understood as a representation of the other in speech. As a subjective and linguistic counterpart to the original speaker $\left(S_{0}\right)$, the addressee $\left(S_{1}\right)$ will act as an anchoring point for the endorsement of representations that $\mathrm{S}_{0}$ rejects or concedes, according to the connective used. 
Then a relation between the connected utterances is also marked, with the location of one utterance relative to the other. My aim here is to try and identify the enunciative operations whereby such inter-subjective and inter-propositional relations are structured by the operator $b u t$.

With the coordinator but, we are dealing with qualitative (as opposed to quantitative) connection, where the connected utterance does not provide a quantitative (i.e. spatio-temporal) location of the validation of the previous one, but operates on its notional properties and subjective endorsement. I propose to examine the construction of referential values and subjective positions in compound utterances connected by but, with a particular focus on the linguistic structuring of indirect mental representations, or implicit meaning. The examples are taken from various political debates or speeches, as well as radio interviews and a few dialogues taken from novels.

\section{But-coordination as a three-term relation: the linguistic construction of an intermediary representation.}

I hypothesize here that indirect meanings or implicatures are not encoded in the utterances prior to their connection, but are linguistically constructed through the association of the enunciative operations marked by but and the structuring operations within the connected utterances.

(1) "What's wrong with him?"

"He's drunk."

"But it's only two o'clock."

"He's been drunk for a long time."

(John Grisham, The Runaway Jury, p.156) 
In this dialogue, the first assertion $(\mathrm{P})$ "he's drunk" refers to a simple representation, but its coordination by the interlocutor to the second utterance "it's only two o'clock" marks a second operation. The connective directs us back to a set of properties that could be associated by the addressee to this representation, i.e. to a series of secondary representations for which the first utterance "he's drunk" could serve as an anchoring point, and therefore could help the addressee endorse and validate. The mere presence of but creates a link between a simple representation and a series of secondary ones, or between $\mathrm{P}$ and its notional domain. It also locates those representations relative to the enunciators in such a way that the speaker of $\boldsymbol{b u t}$ marks a relation of subjective discordance with the addressee as regards the endorsement of one of those secondary representations. The utterance $(\mathrm{Q})$ here introduced by "but it's only two o'clock", will then develop the content (dictum and modus) of one particular representation on which this inter-subjective relation of discordance will bear. The domain of reference allotted to $\mathrm{P}$ by the use of the connective is thus narrowed down by the utterance of $\mathrm{Q}$ for the purpose of enunciative rectification.

Through the connection, an indirect meaning (which I shall call $\boldsymbol{i}$, as in implicit), is built, and can be interpreted so that ' $\mathrm{Q}$ is an occurrence of representation which is exterior to the domain of secondary representations associable with P'. Q therefore both reveals and rejects $i$ : '2 o'clock in the afternoon is no time to be drunk', or 'what you're saying is impossible, abnormal, surprising for me, because Q'. The connective but marks that, according to its speaker $\left(\mathrm{S}_{0}\right)$ (or original enunciator, which serves as the origin for all subjective, qualitative constructions in the field of person, aspect and modality), Q does not belong to the class of occurrences of the notion $\mathrm{P}$, or to its set of properties. 
It is therefore an intermediate mental representation, or referential value ('one can be drunk at any time of the day') which is the target of a qualification, (or rather, with but, of a disqualification), and this intermediate implicit reference (located relative to the addressee) is made explicit and accessible through the coordinated utterance (Q).

It is worth noting that the connection marked by but thus defines a three-term relation rather than a binary one. The connective operates what could be called a form of counter-subordination ('don't think that since P then $\boldsymbol{i}$, for Q) and the propositional content of $\boldsymbol{i}$ is linguistically structured as a mirror image (or reversed value) of Q. These enunciative operations are also exemplified in (2):

(2) He's a cop but he isn't a bastard.

In this example, but $\boldsymbol{Q}$ 'but he isn't a bastard' reveals an implicit relation of subordination between $\mathrm{P}$ 'he's a cop' and $\boldsymbol{i}$ 'a cop is a bastard', where $\mathrm{P}$ has the power to validate $\boldsymbol{i}$ ('since he is a cop, then he must be a bastard'). The speaker $\left(\mathrm{S}_{0}\right)$ implies that, for the addressee $\left(S_{1}\right.$, his subjective counterpart), 'be a bastard' belongs to the set of properties associated to the notion 'be a cop', and rejects this representation, using the subject 'he' as an example. This implicit subordination (located relative to the addressee) is thus both created and disqualified though the use of the connective but. But $\boldsymbol{Q}$ in (2) enables the speaker to create an implicit mental representation such as $\boldsymbol{i}=$ Q'(or $\boldsymbol{i}$ is a reversed representation of Q). What is striking is that the implicit utterance will be exactly the opposite if one changes the modus in Q:

(2') He's a cop, but he is a bastard implies this time that 'cops are usually not bastards'. Furthermore, since Q is determined by the speaker as being the case, the intermediate representation is disqualified: $\boldsymbol{i}$ is not an occurrence of the notional domain of $\mathrm{P}$. 
The construction of reference (and inference) is an important issue here, and in the case of connectives such as but, the distinction between conventional implicature and conversational implicature seems artificial. The speaker's meaning intentions are understood and retrieved because they are linguistically marked, both by the connective and by the semantic and grammatical structure of the connected propositions. Implicit reference and implicatures are clearly built through a complex linguistic process involving back-reference processing and modal positioning.

It should be stressed here that not only does the connective but operate a reconfiguration of the notional domain, it also acts as a modal. Through the use of but, the implicit utterance $\boldsymbol{i}$ is the target of an inter-subjective modality of discordance. $\boldsymbol{i}$ is ascribed to an addressee serving as an anchor point, or medium, for this modality of discordance.

The addressee, as a linguistic representation of otherness, can also take on the role of an alter ego, and, as a springboard for denied implicit representations, it will help us retrieve the speaker's own mental representations. In those cases, but $\boldsymbol{Q}$ will often reveal the speaker's subconscious, as Freud's concept of 'denial' explains ('I dreamt of a woman, but she wasn't my mother'): by refuting an anticipated interpretation attributed to the psychologist, the speaker reveals his own mental representations.

Coordination with $\boldsymbol{b u t}$ is also very interesting to analyse in fiction for its role in the linguistic construction of characters through their speech. In (3) for example:

(3) Dr Herder: His lordship is a paranoid schizophrenic.

Sir Charles: But he's a Gurney !

Dr Herder: Then he's a paranoid schizophrenic Gurney who believes he's God.

Sir Charles: But we've always been Church of England!

(Peter Barnes, The Ruling Class, I.3) 
the character of Sir Charles is partly built through his use of but in his replies : 'But he's a Gurney', following our former analyses, builds an implicit intermediary representation such as 'be a Gurney' cannot be an occurrence of the notional domain associated with 'be a paranoid schizophrenic' and vice versa.

At this stage I would like to go back on the linguistic definitions of some of the concepts I have used so far, such as 'secondary representations associable with $\mathrm{P}$ ', 'notional domain of $\mathrm{P}$ ', 'set of properties of the notion $\mathrm{P}$ ' etc., considering that the connective marks a secondary operation on a predication $\mathrm{P}$ which remains validated and endorsed by the speaker.

I would say that argumentative (or qualitative) connection, whatever connective is used, defines one of the utterances as the anchoring point for the subjective endorsement of the utterance to which it is linked. Two locating operations are therefore marked:

- the location of one predication relative to the other one

- the location of the connected utterances relative to the subjective coordinates $\left(\mathrm{S}_{0}, \mathrm{~S}_{1}\right.$ etc. $)$ of the situation of utterance.

Within argumentative connection, as soon as an utterance is connected with another one, it becomes a kind of macro-notion and is allotted a structured notional domain which I choose to call its argumentative domain. The notional properties of the argumentative domain of such an utterance are to be considered as a bundle or family of other utterances which, from the subjective viewpoint of the speaker, can share its modal endorsement. This family of utterances is made up of all the potential continuations of $\mathrm{P}$, in other words, the implicit utterances which can be validated and endorsed by means of $\mathrm{P}$. The utterance $\mathrm{P}$ thus becomes a potential constitutive 
anchoring point for this bundle of utterances. It is the connective which constructs the very presence of an implicit utterance, its semantic value then depending on the connected predications, as I will develop below.

An utterance thus provided with an argumentative domain through its connection with another one will have the status of anchoring point for the modal endorsement of the other one, in a potential process of qualitative subordination. This location can build various semantic values such as cause, condition, justification etc. but also contradiction and opposition, depending on the connective used and the inner structure of the connected utterances.

The connective but is particularly interesting because:

- it endows $\mathrm{P}$ with an argumentative domain, therefore making it the potential anchoring point for the endorsement of a family of implicit utterances, which creates the existence of indirect meaning

- it opposes speaker to addressee with respect to the configuration of this argumentative domain,

- it introduces an utterance Q which both structures and disqualifies one of the implicit utterances within P's argumentative domain.

The construction of P's argumentative domain is thus re-configured, updated by the speaker, in a relation of inter-subjective discordance: the speakers are not 'on the same wavelength'.

III. The incidence of the inner structure of $P$ and $Q$ on the retrieval of the implicit utterance. 
In the above section, I mentioned the fact that implicit meanings are linguistically constructed through the association of the enunciative operations marked by but and the structure of the connected utterances. The examples given illustrated the case when the propositional content of $\boldsymbol{i}$ was linguistically structured as a mirror image (or reversed value) of Q. In fact, my observation of a large corpus of coordinate clauses connected by $\boldsymbol{b u t}$ revealed two main forms structuring the implicit utterance $\boldsymbol{i}$ :

a) a form in which $\mathrm{Q}$ takes up the grammatical structure of $\mathrm{P}$ with a change of one of its lexical entries or with a different modality $\left(\mathrm{Q}=\mathrm{P}^{\prime}\right)$

b) a form in which Q does not directly take up P but structures a reversed value of $i$ $\left(\boldsymbol{i}=\mathrm{Q}^{\prime}\right.$ or $\left.\mathrm{Q}=\boldsymbol{i}^{\prime}\right)$

It is necessary now to go into more details and analyse the structuring process of implicit utterances according to the form involved, with a close observation of more contextualized examples.

\section{III.1 Form 1: $Q=P^{\prime}$}

(4) (about the war in Iraq)

And now we're fighting them now. And it's hard work. I understand how hard it is. I get the casualty reports every day. I see on the TV screens how hard it is. But it's necessary work.

(G. Bush, First Presidential debate, 30/09/2004)

This rather characteristic example presents a similar grammatical structure in P and Q: it be + adj + work, but with a different instantiation of the adjective. Hard and necessary are not semantically opposed: the connective but defines them as opposed with respect to an argumentative project, a secondary meaning. The change of adjectives in $\mathrm{Q}$ induces a re-configuration (or re-formatting) of P's argumentative 
domain, with the exclusion of one of its potential continuations or implicit utterances: here the predication of a wish to stop fighting in Iraq. The speaker G. Bush ascribes this implicit predication to the addressee (the viewer/his opponent), who serves as a medium for a modality of discordance. For G. Bush, the validated utterance 'it is hard work' does not have a status of locator for the subjective endorsement of such an implicit predication as 'we must stop fighting'. Clearly, in this configuration $(\mathrm{Q}=\mathrm{P}$ '), and unlike the second one $(\mathrm{Q}=\boldsymbol{i}$ '), the exact semantic and grammatical structure of the implicit predication is not always retrievable, but the very presence of such a secondary indirect meaning is definitely made obvious by the use of the connective.

It is important to add, and we will expand further on this phenomenon as we go along, that the inter-subjective relation of discordance marked by but also defines an argumentative hierarchy: the speaker G. Bush posits that difficulty is no sufficient argument for stopping the war; necessity is defined as a stronger argument against this conclusion. G. Bush here appropriates such values as courage in face of adversity (cf. the pronoun 'we'), even though he only shares the soldiers' difficulty 'on the TV screen'. In the process, the problem of the loss of human lives, previously mentioned in the debate by J. Kerry, is rejected by G. Bush as a secondary issue.

In (5) below, the compound utterance delivered by J. Kerry presents the same form where $Q$ takes up the structure of $P$ :

(5) Civilians get onto aircraft, and their luggage is $X$-rayed, but the cargo hold is not X-rayed. Does that make you feel safer in America?

(J. Kerry, First Presidential debate, 30/09/2004)

This time the instantiation of the subject is modified ('the cargo hold' versus 'their luggage') and the assertive modality is reversed (negative versus positive). As a reversed formulation of $\mathrm{P}, \mathrm{Q}$ re-configures P's argumentative domain, so that $\mathrm{P}$ loses its 
status of potential locator for the subjective endorsement of an implicit predication, i.e. here the assertion of civilians' security. This disqualified implicit utterance $(\boldsymbol{i})$ is immediately retrievable, and confirmed by the question that follows: 'Does that make you feel safer in America?'. The connective but posits J. Kerry in a relation of discordance relative to his addressee as regards the nature of P's argumentative domain, then marks the exclusion of one of its potential properties through $\mathrm{Q}$ taking up and modifying its instantiation.

The same process can be found in the following example, which illustrates the importance of the interaction of combined grammatical markers in the linguistic construction of semantic values:

(6) Now we're told by some that law and order shouldn't be made an election issue. But it's not we politicians who make it an election issue. It's you the people.

(M. Thatcher, Birmingham Speech 19/04/79)

Let us first note that the addressees to whom M. Thatcher attributes false implicit predications are here explicitly designated (though with indefinite reference) by the pronoun 'some'. The utterance $\mathrm{P}$ takes the form of indirect speech expressing regret concerning a state of fact ('should not be'). The connected utterance but $\boldsymbol{Q}$ introduces the refutation by M. Thatcher of an implicit accusation defining the Conservative Party as responsible for the choice of insecurity as a main campaign issue. Here again Q takes up the passive structure of $\mathrm{P}$ (with no agent expressed for the predicate 'make') but in a negative cleft sentence. This cleavage operation retrieves the agent of 'make' and marks a contrast on the subject pronoun ('We' $\Rightarrow$ 'you the people'). The implicit accusation is made explicit for rectification.

The enunciative operations marked by but (subjective discordance and disqualification of implicit predications through a re-configuration of P's argumentative 
domain) are best analysed in large discourse extracts, where the role of the connective in the progression of discourse appears decisive. In the following example (7), taken from John Grisham's novel The Runaway Jury, a medical expert is cross-examined during a trial against the tobacco industry. The argumentative stake for the defence is not an easy one: the idea is to exculpate the tobacco industry by demonstrating, not that tobacco has no effect on the smokers' health, but that it is impossible to prove that tobacco is directly responsible for lung cancer.

(7) "Smoking greatly increases the risk of lung cancer."

"But it doesn't cause it every time, does it?"

The connective but instantly marks an inter-subjective relation of discordance between the defendant and the expert. Yet the discordance does not concern the actual validation and endorsement of the expert's utterance $\mathrm{P}$ 'Smoking greatly increases the risk of lung cancer'. This predication is considered as true by both speakers. But its argumentative power, that is, its capacity to validate other potential predications, is refuted by the defendant. But introduces an utterance (Q), which takes up P with a different verb and modality. The same subject 'smoking' is referred to by the pronoun 'it', but 'increase' becomes 'cause' and 'greatly' becomes 'every time'. Through this modification, the issue is diverted from a comparative evaluation of risks to a strict and systematic determination of causality, i.e. whether or not the subject 'smoking' always validates the predicate 'cause cancer'. Moreover, the modality in Q is a negation with a questiontag asking for confirmation. The defendant entices the expert to endorse the negative assertion of Q, which disqualifies one of the implicit utterances in P's argumentative domain (i): 'Smoking causes lung cancer'. Here again, the endorsement of $Q$ as a reconfiguration of $\mathrm{P}$ both reveals and disqualifies this implicit representation. $\mathrm{P}$ can no longer be the locator for the subjective endorsement of $\boldsymbol{i}$. 
The expert's answer satisfies the defence counsel in so far as it confirms the disqualification of an implicit meaning and even makes it explicit:

"No. Not every smoker gets lung cancer."

"Thank you."

The exchange carries on with a series of but connectives, which, on the one hand, maintain the relation of discordance on the speakers' secondary, indirect representations, and, on the other hand, create a to and fro motion on the definition of the argumentative domain of the initial utterance. A linguistic battle starts where each speaker tries to dominate the progression of discourse and have the last word:

"But for those who smoke, the risk of lung cancer is much greater."

"Do you admit that air pollution causes lung cancer?"

"It might. But I stand by my research. Rural smokers get lung cancer more than rural non-smokers, and urban smokers get cancer more than urban nonsmokers".

The expert uses the connective but so as to deviate from the implicit predication of nonsystematic responsibility of tobacco. He thus re-introduces his initial predication $\mathrm{P}$, reformulating his comparative evaluation through the words 'risk' and 'greater', which re-establish a potential responsibility of tobacco on the development of cancer.

The defendant's question: 'Do you admit that air pollution causes lung cancer?' is quite skilful, as it shifts the argumentative issue from the instantiation of the predicate ('cause' versus 'increase the risk of cancer') to the instantiation of the subject for the predicate 'cause lung cancer': 'air pollution' replaces 'smoking', with an interrogative modality. The question of risk is thus discarded, the issue becoming the strict identification of a culprit. The linguistic ploy is obvious: if the expert endorses the assertion 'air pollution causes lung cancer', then the subject 'smoking' is no longer 
alone in validating the predicate 'cause cancer', and the tobacco industry can no longer be proved guilty.

The expert is trapped. He uses but again trying to disentangle himself from the defendant's implicit representations, and to recover his initial utterance $\mathrm{P}$, whose argumentative domain has been completely re-formatted. But the battle is lost. It can also be noted that in answering 'it might', the expert falls even more into the trap. The modal verb marking a potential truth, a risk that pollution (in the same way as tobacco) may cause cancer, then the prosecutor could just as well incriminate any polluting industry.

This exchange illustrates the complex process by which the connective but can help structure indirect representations. Followed by an utterance Q which takes up and reorients the initial utterance $\mathrm{P}$ ('smoking increases the risk of cancer'), but defines an inter-subjective relation of discordance between speakers on P's capacity to be the anchoring point for the endorsement of an implicit predication. But $\boldsymbol{Q}=\boldsymbol{P}$ ' here invalidates the potential endorsement by the addressee of an implicit predication $i$ : 'Tobacco is the only cause of lung cancer'. Although this predication has never been uttered directly, the combined operations described above have made it retrievable.

The same analysis could be made of the rest of the cross examination, which follows the same process:

(8) "I read that report", Dr Kilvan said.

"Do you have an opinion on it?"

"No, heredity is not my specialty."

"So you can't say yes or no on the issue of whether heredity might be related to smoking and lung cancer."

"I cannot".

“But you don't contest this report, do you?

(John Grisham, The Runaway Jury, p.204) 
By modifying the structure of $\mathrm{P}$, the speaker corrects his interlocutor regarding $\mathrm{P}$ 's argumentative domain. In doing so, the speaker overpowers his interlocutor and controls the discourse continuity.

\section{III.2 Form 2: $Q=i$ ' or $i=Q$ ': $i$ is a reversed representation of $Q$}

This configuration has already been mentioned above through the analysis of examples (1) to (3). The construction and retrieval of implicit representations in this case is made easier by the fact that, contrary to Form 1, utterance Q does not necessarily take up the structure of $\mathrm{P}$, but produces a mirror (or reversed) image of the propositional content and modal endorsement of the implicit utterance itself. Illustrations of such uses appear in examples (9) and (10) below, for which I propose a close analysis:

(9) As soon as possible after the election, a Conservative Government will restore service pay to the full amount recommended by the Armed Services Pay Review Board. I know this will increase expenditure, I don't deny it. But there'll be no home policy at all unless we are properly defended because there'll be no home. You can't prosper unless you survive.

(M. Thatcher, Birmingham Speech 19/04/79)

The utterance P ('it will increase expenditure') here contains the modal will, which defines the extra expenditure as inherent to a prospective increase of service pay. The full endorsement of the assertion and its modality by $\mathrm{S}_{0}$ is confirmed by 'I don't deny it'. The utterance Q following the connective but is no contradiction or opposition to this previous assertion $\mathrm{P}$, but introduces a counter-argument to the conclusion $\mathrm{M}$. Thatcher's detractors could draw from P. Using but, she announces a counter- 
subordination and a subjective discordance on P's argumentative domain. One of the potential occurrences of P's domain (and therefore potential conclusions drawn by detractors) is made explicit by the utterance Q: 'there'll be no home policy at all unless we are properly defended because there'll be no home', where unless marks a conditional relation between the existence of an efficient national army and the existence of such things as 'home' and a home policy. The implicit utterance which is disqualified here can therefore be retrieved by reversing this conditional relation in Q: more money for defence means less for home policy.

Hence in Form 2, the connective but, inter-acting with the linguistic operations within $\mathrm{P}$ and $\mathrm{Q}$, builds an implicit utterance where $i$ is a reversed representation of $\mathrm{Q}$ ( $\mathrm{Q}=i$ ' or $\left.i=\mathrm{Q}^{\prime}\right)$. This linguistic pattern is commonly used in political campaign speeches because it enables politicians to manipulate their detractors, to whom they ascribe implicit assertions so as to better disqualify them and introduce their own claims. More than a simple coordinating device, but can therefore be considered on the level of interpropositional and inter-subjective relations as a counter-subordinator, operating a threeterm relation of qualitative locations: $\mathrm{P}$ is defined as the anchoring point for the qualitative endorsement of $\boldsymbol{i}$ by the addressee and at the same time this relation is disqualified by the speaker through $\mathrm{Q}$.

In the following address to G. Bush and the viewers, J. Kerry provides us with a real gloss of this three-term relation of qualitative locations and counter-subordination:

(10) We have to succeed. We can't leave a failed Iraq [assertion of P]. But [subjective discordance on a potential $\mathrm{P} / \boldsymbol{i}$ subordination] that doesn't mean it wasn't a mistake of judgment to go there and take the focus off of Osama bin Laden. It was! [explicit formulation and disqualification of $\boldsymbol{i}$ through the assertion of Q].

(J. Kerry, First Presidential debate, 30/09/2004) 
The linguistic construction of subjective relations is essential here. But invalidates $\boldsymbol{i}$ for being out of P's argumentative domain and irrelevant. In doing so, it also dismisses mental representations that are attributed to the addressee, and reasserts the speaker's authority in the discourse progression. The co-speaker's representations may sometimes be conceded, but they are always presented as beside the point, irrelevant to the ongoing discussion, or simply invalid.

\section{But and the notion of 'argumentative force'}

As illustrated in example (10) above, the enunciative operations described for the connective but are closely linked with another argumentative phenomenon, which has always been analysed within the theoretical framework of pragmatics : i.e. what $\mathrm{O}$.

Ducrot and J.C. Anscombre called 'argumentative force'. ${ }^{4}$ The connective but clearly introduces a hierarchy in the endorsement of discourse : the utterance Q, which is endorsed by the speaker $\mathrm{S}_{0}$ as pre-eminent, operates a qualitative and argumentative boost. Using but, the speaker is setting himself in command of the discursive exchange and taking control of its progression and thematic direction.

\section{IV.1. Inter-subjective relations and discourse orientation.}

The inter-subjective relation of discordance marked by the connective but is very often used in interviews, dialogues or debates precisely because it enables the speaker to dissociate himself from his addressee, divert and re-route the conversation, 
cut the co-speaker short or go back to a former issue. In short, but gives the speaker the power to appropriate the orientation of discourse.

The 2004 first presidential television debate between G. Bush and J. Kerry abounds in such uses of the connective but:

(11) J. Lehrer: We'll come back to Iraq in a moment. But I want to come back to where I began, on homeland security. This is a two-minute new question, Senator Kerry. As president, what would you do, specifically, in addition to or differently to increase the homeland security of the United States than what President Bush is doing? (First Presidential debate, 30/09/2004)

(12) J. Lehrer: New question, two minutes. Senator Kerry, you mentioned Darfur, the Darfur region of Sudan. Fifty thousand people have already died in that area. More than a million are homeless. And it's been labeled an act of ongoing genocide. Yet neither one of you or anyone else connected with your campaigns or your administration that I can find has discussed the possibility of sending in troops. Why not?

J. Kerry: Well, I'll tell you exactly why not, but I first want to say something about those sanctions on Iran.

(First Presidential debate, 30/09/2004)

(13) I'm not going to talk about a difference of character. I don't think that's my job or my business. But let me talk about something that the president just sort of finished up with.

(J. Kerry, First Presidential debate, 30/09/2004)

In the examples above the connective but is always used to set up a subjective discordance between speakers on the continuation of discourse and the choice of topics: the speaker of $\boldsymbol{b u t}$ breaks with the co-speaker's direction and imposes his own.

In the following example, it is the debate moderator, Jim Lehrer, who intervenes in the debate so as to make G. Bush react to one of J. Kerry's previous utterances. It 
must be noted that changing the argumentative direction of an utterance in such a way means going counter to an explicit or implicit potential continuation, so that this operation of subjective discordance and discourse disruption also contributes to the linguistic creation of indirect meaning:

(14) J. Kerry: Just because the president says it can't be done, that you'd lose China, doesn't mean it can't be done. I mean, this is the president who said "There were weapons of mass destruction," said "Mission accomplished," said we could fight the war on the cheap - none of which were true.

J. Lehrer: Thirty seconds, Mr. President.

G. Bush: You know my opinion on North Korea. I can't say it any more plainly.

J. Lehrer: Well, but when he used the word "truth" again...

G. Bush: Pardon me?

J. Lehrer: ... talking about the truth of the matter. He used the word "truth" again. Did that raise any hackles with you?

G. Bush: Oh, I'm a pretty calm guy. I don't take it personally.

(First Presidential debate, 30/09/2004)

In his first answer to J. Kerry, G. Bush clearly refuses to discuss the issue of North Korea, and completely ignores his opponent's accusations of untruthfulness. J. Lehrer, expecting a reaction, uses the connective but to break into the exchange and give back to J. Kerry's utterance an argumentative power which had been denied or ignored by G. Bush. This discordant steering of the debate is introduced by but and followed with a reference to an element of J. Kerry's utterance aimed at provoking a reaction ('He used the word "truth" again. Did that raise any hackles with you?'). But G. Bush here maintains his course of argumentation and is not disturbed by Lehrer's strategy.

The operation of discourse switching or re-orientation marked by but is also quite clear in the following example, taken from an interview of M. Moore by the journalist A. Collins, and which I propose to analyse in its progression: 
(15) Michael Moore: I wouldn't know how to organise myself to film so that B follows A and C follows B. I don't think you should do that, especially a documentary film like this. Your feet should not be in cement. You should be open to whatever happens and go with it. It drives the budget and the producers batty because it can get costly but if you're willing to do that you'll end up with something that will reach a wider audience because you've got a much more interesting film.

Andrew Collins: But documentary can be as manipulative as fiction, can't it? If you want to make it that way, you can make the facts fit.

MM: But that's true of anything.

AC: But you're led by the subject rather than the other way around. Some documentary film-makers just make the films that they want to make, they know what they want to make before they start.

(Guardian interview of M. Moore by Andrew Collins, 11/11/2002)

The first use of the connective but in M. Moore's speech is non-dialogical and marks that the absence of pre-established framework in documentary films is more important to him than the financial problems this openness can cause. It is noticeable that starting from this assertion, the dialogue between M. Moore and A. Collins is then built on a series of subjective dissociations and disqualifications of implicit meaning. The journalist first intervenes with a connective $\boldsymbol{b u t}$ so as to redirect the conversation on the ideological rather than the artistic implications of Moore's assertion. Taking up M. Moore's predicative relation <generic 'you' + 'should' + 'be open'> to question its validity in the particular domain of documentary films, the journalist re-formulates Moore's utterance $\mathrm{P}$ in 'But documentary can be as manipulative as fiction, can't it? If you want to make it that way, you can make the facts fit.' (form 1: Q=P'), by modifying its modality ('should' becomes 'can') and suggesting an opposite predicate (from 'be open' to 'be manipulative'). By doing so, Andrew Collins rectifies P's domain and launches a discordant argumentative progression on the implicit qualities of 'objective 
truth' which could be associated with documentary films on account of their improvised form. The process of counter-subordination is here again exemplified: an implicit mental representation is thus structured, attributed to his co-speaker, and disqualified. The connective but, cooperating with contextual markers, constructs the presence of innuendoes as well as a subjective dissociation of the journalist from his interviewee. A. Collins's following utterance ('you can make the facts fit') is a development of Q, where the pronoun 'you' is ambiguous and could be interpreted as generic or as referring to M. Moore specifically, thus adding to the slight provocation.

Quite adequately, M. Moore also starts his answer with the connective but so as to dissociate himself from A. Collins, but uses the very same argumentative strategy. Taking up the journalist's predicative relation 'documentary can be as manipulative as fiction' as valid whatever the subject ('But that's true of anything), M. Moore disqualifies his interviewer's implicit (but perfectly understood) personal accusation. The journalist then tries to adjust the fire, rectifying, not what he said, but the implicit meaning he has created. In his utterance: 'But you're led by the subject rather than the other way around. Some documentary film-makers just make the films that they want to make', A. Collins clearly contrasts the pronoun 'you' with 'some documentary filmmakers', using but again, which could be paraphrased as 'don't think that my predication was aimed at you specifically, because my use of the pronoun 'you' was a generic one..'.

The use of the connective but in interviews and debates is particularly revealing of an enunciative fight for the control of the orientation and direction of discourse. The co-speakers' utterances are thus taken up and corrected, not in their validation itself, but in their power to validate implicit ones, and this operation of counter-subordination is 
the result of a double process of inter-subjective location and linguistic reformatting of argumentative domains.

\section{IV.2. Counter-subordination and argumentative force}

This operation of counter-subordination seems to me to be the linguistic origin of what is called in pragmatics the 'argumentative force' of an utterance. Through the enunciative operations marked by but, utterance $\mathrm{Q}$ is endowed with stronger argumentative force precisely because it introduces an element which disqualifies and overpowers a former relation, and also because it defines an inter-subjective relation of discordance on the endorsement of this former relation. I might add that the inter-subjective locations cannot but be taken into account as an essential parameter in the linguistic analysis of argumentative connection.

The status of stronger argument which is ascribed by but to utterance Q, is quite often explicitly paraphrased in the utterance itself :

(16) I shot the entire movie in continuity, but more importantly I shot the entire Omaha Beach sequence in continuity. (S. Spielberg, DGA Magazine, January 1999, interview about the making of Saving Private Ryan)

(17) People are still hurting in the state of Michigan. I know that. I travelled here a lot, I heard the stories. But the fundamental question is, which candidate can continue to grow this economy? And that's George W. Bush. (President Bush's Radio Address, 10/30/2004 )

Yet these paraphrases are redundant, or emphatic, because the stronger status of the argument developed in Q is linguistically constructed through connection itself. Example (18) below is very interesting to analyse in detail in that respect : 
(18) Read the letter sent to me by Dr Safa Hashim, who lives here in Glasgow, and who says he is writing despite his fears of Iraqi retribution. [He says the principle of opposing war by the public is received warmly by Iraqis for it reveals the desire of people to avoid suffering. But he says it misses the point because the Iraqi people need Saddam removed as a way of ending their suffering.]

(T. Blair,15/02/2003 speech on Iraq)

The interaction of such connectives as but, for and because in this utterance by an Iraqi doctor, quoted by Tony Blair in one of his pro-war speeches, again illustrates the process of counter-subordination marked by but, and also reveals the setting up of a scale of argumentative power given to the utterances. This scale is certainly not a logical one, but rather a subjective evaluation marked by specific linguistic operators. The argumentative domains structured in the utterances $\mathrm{P}$ and $\mathrm{Q}$ on either side of the connective but are developed through the use of qualitative connections introduced by for and then because. These conjunctions also mark inter-propositional as well as inter-subjective locations. The connective but will define the second location (marked by because) as superior to and disqualifying the first one (marked by for), in a complex combination of operations:

\begin{tabular}{|c|c|c|}
\hline $\mathrm{P}[\mathrm{U} 1 \text { for } \mathrm{U} 2]^{5}$ & but & Q [U1' because U2'] \\
\hline $\begin{array}{l}\text { desire to avoid suffering (U2) } \\
\text { locates (cf. for) the endorsement by } \mathrm{S}_{0} \\
\text { of: is received warmly (U1) }\end{array}$ & but & $\begin{array}{l}\text { need to end suffering (U2') locates } \\
\text { (cf. because) the endorsement by } \mathrm{S}_{0} \\
\text { of: misses the point (U1') }\end{array}$ \\
\hline
\end{tabular}

Several remarks must be made about this compound utterance:

- $\quad$ P and Q present a parallel complex structure, Q taking up the predication expressed in $\mathrm{P}$ with a change of predicates ('desire to avoid' $\Rightarrow$ 'need to end') but keeping the same complement 'suffering'. We are dealing with Form 1 here $(\mathrm{Q}=\mathrm{P}$ '). 
- $\quad$ The qualitative connection with for within P is also interesting: as is the case in any argumentative subordination, this connective marks that the validation of U2 ('it reveals the desire of people to avoid suffering') is set as the anchor point, or locator, for the validation and endorsement of the predicative relation in U1 ('the principle of opposing war by the public is received warmly by Iraqis') U1 thus belongs to the set of properties included in U2, i.e. to its argumentative domain. But, on the level of intersubjective relations, for marks the argumentative relation as thematic or preconstructed, i.e. non-polemical, taken for granted and endorsed by any potential addressee. The particularity of this connection is that even though the locating argument (Q) is new and introduced by the speaker himself, its argumentative domain is at once represented as consensual. Argumentation introduced by for is thus added to U1 but not necessary to U1. In that respect, I would say that for coordinates U1 with a kind of argumentative subordination that is appositive rather than determinative, to use terms commonly applied to describe relative clauses: 'I assert U1, and I remind you, if need be, that U2 locates U1.'

- $\quad$ On the other hand, the argumentative subordination marked by because in $\mathrm{Q}$ sets the validation and subjective endorsement of U2' as determinative for the endorsement of U1', so that the inter-subjective relation is here completely different. The argumentative relation is defined as rhematic, the speaker introducing an argument which he endorses personally, in a potential discordance with his addressee. Contrary to for (and since, for that matter), because builds an argumentative link which is not granted in advance, but can still be discussed. In that respect, because is particularly compatible with $\boldsymbol{b u t}$, which operates a preliminary discordance on P's argumentative domain. 
- But counters the subordination explicitly expressed by for, breaks with the consensual endorsement of $\mathrm{U} 1$ in $\mathrm{P}$, and introduces a new argument which, as a result, gains a priority status.

\section{When but can build notions of explanation and condition.}

Semantic values such as explanation or condition can sometimes be retrieved in but compound-utterances. It appears that the linguistic construction of these relational notions can also be explained by the operations described above, i.e. the process of counter-subordination and the organization of argumentative domains into a hierarchy. There again, the core-operation of the connective but will interact with other linguistic operations within the connected utterances in the complex process of meaning construction. In (19), for example:

(19) Storywise, I stuck to written script very closely, but I had a very good written script.

(S. Spielberg, DGA Magazine, January 1999, interview about the making of Saving Private Ryan)

The relation between $\mathrm{P}$ and Q can be paraphrased in (19) as a restrictive explanation, such as 'I usually don't stick to written script, but this time I did, only because I had a very good script'.

The utterance $\mathrm{Q}$ is here set as a better anchoring point for the validation and endorsement of $\mathrm{P}$, than another potential, implicit one (such as 'I always do'). The connective but, as always, operates a counter-subordination, but in this pattern, it disqualifies $\boldsymbol{i}$ as an argument for $\mathrm{P}$ (and not $\mathrm{P}$ as an argument for $\boldsymbol{i}$, as was the case is 
former examples) and posits $\mathrm{Q}$ as a better argument. This operation thus introduces $\mathrm{Q}$ as the right explanation for $\mathrm{P}$, as opposed to an implicit one.

The notion of restrictive explanation in such utterances connected by but originates in its double process of subjective rectification and hierarchical organization of argumentative domains. The same process explains the conditional relation between Q and P that can be retrieved in example (20):

(20) Yes, let the United Nations be the way to deal with Saddam. But let the United Nations mean what it says; and do what it means.

(T. Blair, 15/02/2003 speech on Iraq)

In this example, but links two pseudo-imperative predications (therefore predications which are not validated in the situation of utterance) in such a way that the second one is set as the conditional anchoring-point for the concession of the first one : 'ok for the prospective validation of $\mathrm{P}$, providing that $\mathrm{Q}$ is also validated'. Tony Blair here imposes $\mathrm{Q}$ as a prerequisite for the acceptance of the UNO as the one to deal with Saddam. This notion of 'restrictive condition', or 'prerequisite', appears clearly in another possible paraphrase of the utterance; 'ok but first let the UN mean what it says'. This conditional relation is due to the fact that, interacting with the modality in both of the connected utterances, but defines $\mathrm{Q}$ as a priority locator for the endorsement of a potential acceptance of $\mathrm{P}$. The connective but thus operates a shift in responsibilities: the validation and endorsement of 'let' no longer depend on the speakers, they are subordinate to the validation of $\mathrm{Q}$.

It is worth noting that with but, the conditional relation is set in reverse order compared to the one built by the connective and linking an imperative predication with a back reference assertion. The famous example: ${ }^{6}$

(21) Think of baked beans and you think of Heinz 
can be analysed as the fusion, through the use of the connective and, of two notional domains. The two mental representations are associated in such a way that the suspended validation of $\mathrm{P}$ (cf. the imperative modality) is set as the anchoring point for the validation of Q (if you think of baked beans, then you think of Heinz). Using but instead of and in (21') :

\section{(21') Think of baked beans but think of Heinz}

one realizes that it is no longer possible to take up the potential subject you in the second predication because the order of locations is reversed : this time it is utterance Q which gains the status of conditional anchoring point for the endorsement of P: 'it's ok for you to think of baked beans, providing they're Heinz..'

\section{Conclusion}

As is the case with most discourse connectives, various meanings or referential values can be retrieved from the use of but. Yet considering connectives as simply polysemic does not help us understand the process by which grammatical markers can contribute to the construction of meaning, whether explicit or implicit. My aim here was to propose a contextualized analysis of but which would both help reveal its core operation and the intra-linguistic contextual parameters with which it can interact to build a final referential value. Even though the extra-linguistic context can certainly modify or influence the interpretation of an utterance, argumentative or 'pragmatic' phenomena can still be analysed without necessarily resorting to extra-linguistic tools, in so far as they are subjective representations built by specific linguistic operations. As regards the connective but, its argumentative power appears to be due to the 
enunciative operations it marks, in association with the inner-structures of the utterances it links:

a) The indirect, implicit meaning that can be retrieved through its use is no common extra-linguistic knowledge or "topos" ${ }^{7}$; its presence stems from the linguistic construction of an argumentative domain which is attributed, through the connective but, to the first utterance in the compound structure $(\mathrm{P})$. This domain can be understood as a bundle of implicit utterances defining P's notional properties.

b) But also operates a relation of inter-subjective location whereby the speaker is set in a position of discordance relative to his addressee on the endorsement of one of the implicit utterances in P's argumentative domain. This implicit utterance is selected by the introduction of the second utterance in the compound structure $(\mathrm{Q})$ and revealed by its inner structure according to two main configurations $\left(\mathrm{Q}=\mathrm{P}^{\prime}\right)$ and $\left(\mathrm{Q}=\boldsymbol{i}^{\prime}\right)$, but other forms can also be found, especially when but interacts with other connectives.

c) The implicit representation is both revealed and denied in the process of counter-subordination and subjective discordance marked by but. The speaker of but thus appropriates the discourse continuation through a double process of subjective and propositional locations in a three-term relation, one of the terms being a linguistically constructed implicit one. 


\section{References}

Anscombre, J. C. 1995. Théorie des topö̈, Paris : Kimé.

Anscombre, J.C., Ducrot, O. 1983. L'argumentation dans la langue. Bruxelles: Pierre Mardaga,

Bouscaren, J., Chuquet, J., Danon-Boileau, L. 1992. Introduction to a Linguistic Grammar of English. An Utterer-centred Approach. Gap: Ophrys.

Culioli, A. 1990, 1999. Pour une linguistique de l'énonciation. Vol.1: Opérations et représentations; Vol.2: Formalisation et opérations de repérage; Vol.3: Domaine notionnel. Gap: Ophrys.

Ducrot, O. 1980. Les échelles argumentatives. Paris : Minuit.

Ducrot, O. 1980 Les mots du discours. Paris : Minuit.

Gournay, L. 2002. « Nothing but but. Opération sémantique et caractérisation syntaxique ». Travaux du Cerlico 15. Presses Universitaires de Rennes.

Groussier, M.L. \& Rivière, C. (Eds.) 1997. La Notion, actes du colloque La Notion, HDL, Gap :Ophrys.

Liddle, Michael (ed.). 1995. Antoine Culioli. Cognition and Representation in Linguistic Theory. C.I.L.T. Vol. 112. Amsterdam: John Benjamins.

Perrin, I. 1992. "Think of baked beans and you think of Heinz": les impératifs dits "conditionnels" in TELOS 1: Approches énonciatives de l'énoncé complexe, Louvain : Peeters.

Sekali, M. 1991. "Connexion inter-énoncés et relations intersubjectives: because, since et for.", Langages $\mathrm{n}^{\circ} 104$.

Sekali-DeCola, M. 1992. «Intersubjectivité et implicite par la connexion inter-énoncés: une étude du connecteur anglais BUT», in TELOS 1: Approches énonciatives de l'énoncé complexe, Louvain : Peeters.

Sekali, M. 1992. "Subordination temporelle et subordination subjective: l'exemple de since.», Travaux du CERLICO $n^{\circ}$ 5, Subordination/Subordinations. Presses Universitaires de Rennes.

Sarfati, G. E. 1995. «Pragmatique et sens commun, note pour une pragmatique topique », Mélanges David Gaatone, Amsterdam : Benjamin, Linguisticae Investigationes, 363-370.

Simonin, J. 1975. "Pour une typologie des discours", in J. KRISTEVA et al. eds. Langue, discours, société: Pour Emile Benveniste, Paris : Editions du Seuil. 85-121.

Simonin, J. 1984. "De la nécessité de distinguer énonciateur et locuteur dans une théorie énonciative", in: Revue du DRLAV n 30, Paris VIII - Vincennes. 55-62 
Yaguello, M. (ed.). 1994. Subjecthood and Subjectivity. The Status of the Subject in Linguistic

Theory, HDL: Ophrys.

\footnotetext{
${ }^{1}$ See Culioli 1990-1999.

2 See Anscombre \& Ducrot 1983, Ducrot 1980, and Anscombre 1995.

${ }^{3}$ For a technical definition of the concept of 'notional domain', see Culioli 1999, Vol.3.

${ }^{4}$ See Anscombre \& Ducrot 1983 and also Ducrot 1980.

5 U1 and U2 stand for 'Utterance 1' and 'Utterance 2'

${ }^{6}$ Example borrowed from Perrin 1992.

${ }^{7}$ See Anscombre 1995 and Sarfati 1995
} 